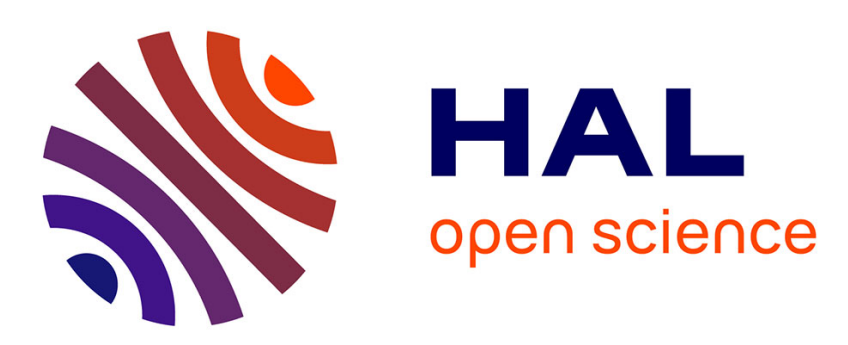

\title{
Operational and economic efficiency analysis of public hospitals in Greece
}

George Fragkiadakis, Michael Doumpos, Constantin Zopounidis, Christophe Germain

\section{- To cite this version:}

George Fragkiadakis, Michael Doumpos, Constantin Zopounidis, Christophe Germain. Operational and economic efficiency analysis of public hospitals in Greece. Annals of Operations Research, 2016, 247 (2), pp.787 - 806. 10.1007/s10479-014-1710-7 . hal-01414677

\section{HAL Id: hal-01414677}

https://hal-audencia.archives-ouvertes.fr/hal-01414677

Submitted on 14 Dec 2016

HAL is a multi-disciplinary open access archive for the deposit and dissemination of scientific research documents, whether they are published or not. The documents may come from teaching and research institutions in France or abroad, or from public or private research centers.
L'archive ouverte pluridisciplinaire HAL, est destinée au dépôt et à la diffusion de documents scientifiques de niveau recherche, publiés ou non, émanant des établissements d'enseignement et de recherche français ou étrangers, des laboratoires publics ou privés. 


\title{
OPERATIONAL AND ECONOMIC EFFICIENCY ANALYSIS OF PUBLIC HOSPITALS IN GREECE
}

\section{http://dx.doi.org/10.1007/s10479-014-1710-7}

\author{
George Fragkiadakis ${ }^{1}$, Michael Doumpos ${ }^{1}$, Constantin Zopounidis ${ }^{1,2 *}$, Christophe \\ Germain $^{2}$ \\ ${ }^{1}$ Technical University of Crete, School of Production Engineering and Management, \\ Financial Engineering Laboratory, University Campus, 73100 Chania, Greece \\ ${ }^{2}$ Audencia Nantes School of Management, France
}

\begin{abstract}
The continuous growth of hospital costs has driven governments in many countries to seek ways to improve their efficiency. In Greece, this has consistently been a major issue for almost two decades, as efficiency assessment and monitoring systems are lacking. In response to this need, the evaluation of the National Health System hospitals' efficiency level is a precondition for planning, implementing and monitoring any promising reform. In this paper, a non-parametric modeling approach is employed to assess and analyze the efficiency of 87 Greek public hospitals over the period 2005-2009, using data envelopment analysis. The operational and economic aspects of the hospitals' operation are considered on the basis of their service/case mix and cost structure. We also investigate the efficiency trends over time with the Malmquist index and a second stage regression analysis is performed to explain the operational and economic efficiency results in terms of the hospitals' operating characteristics and the environment in which they operate.
\end{abstract}

Keywords: Hospital efficiency, Technical efficiency, Data Envelopment Analysis

\section{INTRODUCTION}

Throughout the world, healthcare systems have been under increasing pressure to improve performance by controlling costs without compromising the quality of the provided services

\footnotetext{
* Corresponding author: Constantin Zopounidis, e-mail: kostas@dpem.tuc.gr, Tel. +30-28210-37236, Fax: +3028210-69410
} 
and access to them. This has become particularly important after the outbreak of the recent economic crisis, which has led to tightening public budgets that have also affected healthcare.

In May 2010 "The Economic Adjustment Programme for Greece” was established. The memorandum between Greece, the International Monetary Fund, and the European Union, puts emphasis on the implementation of extensive structural reforms and expenditure cuts in order to restore the competitiveness of the Greek economy and cut down the existing budget deficit. The healthcare sector is one of the main areas where particular emphasis has been put, taking into consideration the significant rise in public health expenditure in Greece over the past decade. The implementation of the program's policies is expected to have a major effect on the healthcare system in the country.

The success of this effort depends, among others, on the successful implementation of policies to improve the utilization of the available resources. Hospital managers play a central role in achieving this goal. From that perspective, achieving a high level of managerial efficiency is crucial. Chilingerian and Sherman (1990,2011) consider managerial efficiency as the production of nursing care, diagnostic/therapeutic services, and treatment programs of satisfactory quality, using the least resources. In this context, hospital managers have to set up and implement policies for controlling labor, medical supplies, and all expenditures related to nursing, intensive care, emergency care, and ancillary services, without sacrificing the quality of the services provided to patients.

It is widely known that the efficiency of hospitals is complicated and multifaceted, as both clinically and managerial efficiency should be achieved. From a clinical perspective, it is the physician's decision making (i.e., patient management) that matters in order to provide high quality medical services on the basis of the complexity and severity of each patient (i.e., utilization of minimum clinical resources to provide quality treatment to patients taking into consideration the complexity of each case). Non-clinical managers, on the other hand, are responsible for the overall operation of a hospital (Chilingerian and Sherman, 1990, 2011), including the management of supplies, human resources, and all kinds of operating costs. Efficiency measurements performed in such a context should be an integral part of a holistic system for evaluating, monitoring, and benchmarking the overall performance of a hospital in combination with additional factors such clinical processes quality and patient satisfaction (Grigoroudis et al., 2011; Patel et al., 2008).

In this framework, our research focuses on the evaluation of the overall managerial efficiency of the acute care hospitals in Greece on the basis of the services they provide and their costs. In particular, we consider the operational and economic efficiency of Greek public 
hospitals using a data set over the period 2005-2009, during which the Greek NHS has faced significant cost increases that have contributed to the deficits of the government's budget. The study is based on data envelopment analysis, which enables efficiency assessments in a multidimensional input/output framework. The overall efficiency of the hospitals is assessed in two main dimensions that cover their operation (service/case mix) and cost structure. In order to obtain insights into the efficiency results, a second stage regression analysis is performed taking into account a rich set of variables related to particular aspects of the service/case mix of the hospitals, their cost structure and human resources, as well as their size, and the characteristics of the external environment in which they operate. Finally, in contrast to previous studies for Greek public hospitals (Aletras et al., 2007; Athanasopoulos et al., 2001; Dimas et al., 2012; Giokas, 2001; Kounetas and Papathanassopoulos, 2013; Mitropoulos et al., 2013), that have relied on static data (e.g., one or two years, mostly prior to 2005), our five-year panel data set enables the analysis of the dynamics of the efficiency results over time. The Malmquist index is used for this purpose and its main constituents provide insights on the factors that drove the efficiency and productivity changes in Greek hospitals during the examined period.

The rest of the paper is organized in five sections as follows. In section 2 we outline the context of the study focusing on the structure of the Greek NHS and the existing literature on healthcare efficiency measurement in Greece and internationally. Section 3 introduces the theoretical framework of the study, as well as the modeling specifications used to assess the efficiency of health units. In section 4 we focus on the empirical results of the study, whereas section 5 concludes the paper and discusses some future research perspectives.

\section{STUDY CONTEXT}

\subsection{The Greek National Healthcare System}

The main characteristic of the Greek NHS since its foundation has been its decentralized structure. The significance and importance of this feature has increased particularly after 2000. The establishing law of the Greek NHS in 1983 anticipated the creation of strong regional health authorities assigned with a wide range of administrative tasks. The founding act of the Greek NHS introduced a regional structure, allowing local administrations to play an important role in determining responsibilities and to formulate proposals to better address 
local needs. However, the reform failed to be implemented fully leaving the health system fully dependent on the central government.

The reform interventions of 2001 and 2003 launched an explicit, institutionally regulated process of structuring the regional health systems and welfare, assigning regional administration with responsibilities for strategic and operational decisions. The Ministry of Health had the role of policy planning at the national level. Overall 17 local administrative units were established, but the reform became inactive during 2004 and new legislation was passed in 2005. Ultimately, a new administrative structure was introduced in 2007 based on seven regional health administrations.

The Greek NHS combines models based on private and public healthcare services, with the public sector being the dominant one. Public hospitals cover about $70 \%$ of the total number of beds, whereas public financing accounts for approximately $60 \%$ of total health expenditure. Public financing is provided either directly by central government or through public social insurance funds. According to data from the World Health Organization, the health expenditure per capita in Greece has increased from $\$ 920$ in 2000 to more than $\$ 3,000$ in 2008 , with a decrease to $\$ 2,730$ in 2010 . The total health spending in Greece accounted for $10.2 \%$ of GDP in 2010, above the average of $9.5 \%$ in OECD countries (OECD, 2012). A significant part (about 25\%) of the total spending involves pharmaceuticals (Ifanti et al., 2013; Vandoros and Stargardt, 2013). In fact Greece has become one of the highest spending countries on pharmaceuticals in OECD.

The Greek healthcare system has consistently faced serious problems concerning its organization, financing, and quality of the provided services. Among other problems, Economou (2010) emphasizes: (a) the absence of cost-containment measures and welldefined funding policies, (b) the lack of incentives to improve performance in the public health sector, (c) the unequal regional distribution of health resources, (d) the lack of planning and coordination, (e) the oversupply of physicians, (f) irrational pricing and reimbursement policies. Naturally, these persistent and unresolved problems have not only led to financial and operational difficulties, but also resulted to low satisfaction as perceived by the citizens.

\subsection{Literature review}

Evaluating the efficiency of healthcare units requires the consideration of quality and quantity of the services they provide as opposed to the resources they employ (e.g., staff, beds, costs, supplies). In this multidimensional input/output context, several parametric 
statistical/econometric and non-parametric (mathematical programming-based) methods have been used (for overviews, see Hollingsworth and Peacock, 2008; Worthington, 2004). Among these approaches, data envelopment analysis (DEA; Charnes et al., 1978, 1994) has become particularly popular for assessing the efficiency of healthcare units, with many applications in Greece as well as in Europe and the rest of the world (Burgess and Wilson, 1998; Chang et al., 2004; Grosskopf et al., 2001; Jacobs et al., 2006; Ozcan, 2008; Shelton Brown and Pagán, 2006; Simoes and Marque, 2011; Steinmann et al., 2004; Sulku, 2012). Hollingsworth (2008) provides a review of 317 published papers on frontier efficiency measurement in healthcare, concluding that even though there is an increasing use of parametric techniques, such as stochastic frontier analysis, around $75 \%$ of the papers use DEA. O'Neill et al. (2008) categorized the DEA models used in healthcare efficiency assessment in four groups on the basis of whether allocative (cost) efficiency and multiple time periods are used in the analysis. According to their review of the literature, up to mid 1990s most studies involved USA, but over the years the number of studies focusing on Europe and other areas has increased.

Most of the studies for the assessment of Greek public hospitals used DEA in order to examine the operational efficiency of healthcare units. Athanassopoulos et al. (1999) measured the technical efficiency and the efficiency of distribution, with data relating to 1992, in 98 Greek hospitals, under constant and variable returns to scale. The study showed a higher efficiency of suburban and rural hospitals than in large cities due to over-concentration of human and financial resources in large cities. However, the results of the follow-up study by Athanassopoulos and Gounaris (2001) indicate that this finding is sensitive to the use of alternative prices for estimating the costs of each hospital. In a similar context, Garcia-Lacalle and Martin (2010) reported further results for Spanish hospitals, and found that large rural hospitals were more efficient, whereas hospitals located in areas where the population to bed ratio is low, tend to be less efficient as they are larger than the real needs of local communities.

The study by Zavras et al. (2002) evaluated the relative efficiency of the primary services of the Social Insurance Institute, based on data for 133 primary healthcare centers across the country using data for 1998-1999. The authors used as input variables, the number of personnel (divided into several categories), and the population covered by each center, whereas the outputs involved the number of patient visits. According to the results, primary healthcare centers with the technological infrastructure to perform laboratory or radiological examinations showed the highest efficiency. Moreover, the medium-sized units, covering population areas of 10,000 to 50,000 , were the most efficient. The efficiency of primary 
healthcare units has also been investigated in other countries (see for instance, Amado and Dyson, 2008; Giuffrida and Gravelle, 2001).

The study of Kontodimopoulos et al. (2006) also focused on primary care centers. The authors assessed the technical efficiency of a group of 17 small-scale hospitals (hospitalhealth centers) for 2003. These hospitals are located in rural areas (covering a population of at most 20,000 people) providing primary, secondary healthcare, and preventive services. An input-oriented DEA model was applied under the assumption of constant returns to scale using as input variables, the number of doctors, nurses and beds. On the other hand, the outputs involved visits to outpatients and medical services provided. The results showed that the efficiency of the hospitals ranged at about $75 \%$.

Another study by Aletras et al. (2007), measured the technical efficiency and scale efficiency in 51 general hospitals in the Greek NHS for the years 2000 and 2003. The purpose of this study was to compare the efficiencies of the hospital before and after the implementation of the reform act 2889/2001, which provided administrative and financial independence of inputs chosen by hospitals. The inputs used in the study included the total number of doctors, other staff and the number of beds. The outputs involved the total number of inpatients, the number of surgeries, the visits to outpatient clinics, as well as laboratory tests, and the number of inpatients adjusted on the basis of the Roemer severity index/complexity index. The study concluded that the implementation of the reform act has affected negatively the hospitals' efficiency. This is contrast to the finding of O'Neill et al. (2008), who noted that reforms made in other European counties had (in most cases) positive results. Such reforms, have been primarily focused on financing issues (Hellowell, 2013), changes in ownership (Hagen and Kaarbøe, 2006; Tiemann et al., 2012), decentralization (Garcia-Lacalle and Martin, 2010, Schmid and Ulrich, 2013), and the introduction of new reimbursement systems (O’Reilly et al., 2012; Or, 2014).

Finally, two recent studies include those of Mitropoulos et al. (2013) and Dimas et al. (2012). Mitropoulos et al. (2013) evaluated the efficiency of public hospitals with two alternative conceptual models. First they considered a model involving resource usage (production efficiency), while the second model focused on financial results (economic efficiency). They employed a sample of 96 general hospitals for 2005. The results indicated that, although the average efficiency scores in both models have remained relatively stable compared to past assessments, internal changes in hospital performances do exist. The authors also used a second-stage regression model to explain the efficiency results in terms of the size of the hospitals, their occupancy rates, and the length of stay. Such regression models are 
often used to gain insights into the main efficiency drivers and facilitate the formulation of policy recommendations (Ferrier and Valdmanis, 1996; Lindlbauer and Schreyögg, 2014; Nedelea and Fannin, 2013). On the other hand, Dimas et al. (2012) evaluated the productive performance, efficiency, and technology changes of 22 Greek public general hospitals for the period 2003-2005. The results suggest that productivity changes were dominated by the technical change component while hospital's inefficiency was attributed to an excessive increase of their expenditures.

The above literature review on the efficiency of Greek public hospitals indicates that most studies have relied on outdated data usually in a static framework. The present study extends previous results on a panel data set covering the period up to the beginning of the economic crisis in the country, during which the inherent problems of the Greek NHS were intensified, thus leading to a new series of reform attempts.

\section{METHODOLOGICAL FRAMEWORK}

This study focuses on the assessment of public hospitals in Greece from the perspective of managerial efficiency, seeking to assess the ability of the hospitals to utilize the available human, technical, and economic resources to produce services in the most efficient and effective manner. Chilingerian and Sherman (1990, 2011) discuss the differences between this approach and the alternative perspective that focuses on clinical efficiency, which is oriented towards patient management, i.e., the utilization of minimum clinical resources to provide high quality treatment to patients taking into consideration the complexity of each case.

In Greece, data associated with qualitative information involving the evaluation of the treatment provided in patients are not yet available. A new initiative towards this direction (Diagnostic Related Groups of patients), has started to be implemented at the end of 2011 and is still in its very early stages to provide useful data. Therefore, in this study we focus on decisions taken by the managers of the hospital and/or health administration regions in relation to the quantity and distribution of inputs within a hospital or health district. The analysis is organized around the two main dimensions of managerial efficiency, namely operational and economic efficiency. In this section we first provide a brief outline of data envelopment analysis and then discuss the proposed model specifications.

\subsection{Data envelopment analysis}


DEA, first introduced by Charnes et al. (1978), is a very useful methodology in the context of benchmarking the operation of healthcare units, as it enables the assessment of productivity and efficiency of organizational units, like hospitals, which use multiple resources to produce multiple products.

The main objective of DEA is to find an efficiency frontier formed by those combinations of resources which optimize the amount of outputs produced, while minimizing the input resources. DEA extends simple input/output ratios, through the consideration of multiple inputs and outputs, to provide estimates of technical efficiency. As noted by Magnussen (1996) a hospital is said to be technically efficient if an increase (decrease) in an output (input) requires a decrease (increase) in at least one other output (input). The multidimensional efficiency frontier introduced by DEA provides a reference for benchmarking the efficiency of all operational decision making units.

Under constant returns to scale (CRS) and with an input orientation for a data set involving $N$ hospitals described over $K$ inputs and $M$ outputs, the maximum efficiency of a hospital $i$ can be estimated through a linear programming model, which is expressed in dual form as follows (CCR model; Charnes et al., 1994):

$$
\begin{array}{ll}
\min & F=\theta_{i}^{C}-\varepsilon\left(\mathbf{1} \mathbf{s}_{i}^{I}+\mathbf{1} \mathbf{s}_{i}^{O}\right) \\
\text { Subject to: } & \mathbf{X} \boldsymbol{\lambda}-\theta_{i}^{C} \mathbf{x}_{i}+\mathbf{s}_{i}^{I}=\mathbf{0} \\
& \mathbf{Y} \boldsymbol{\lambda}-\mathbf{s}_{i}^{O}=\mathbf{y}_{i} \\
& \boldsymbol{\lambda}, \mathbf{s}_{i}^{I}, \mathbf{s}_{i}^{O} \geq \mathbf{0}, \theta_{i}^{C} \in \square
\end{array}
$$

where $\mathbf{X}$ is a $K \times N$ matrix with the hospitals' inputs, $\mathbf{Y}$ is a $M \times N$ matrix with the outputs, $\mathbf{s}_{i}^{I}$ and $\mathbf{s}_{i}^{O}$ are the vectors of slack variables for the inputs and outputs, respectively, indicating the improvements that an inefficient hospital should achieve in order to become efficient, 1 denotes a vector of ones, and $\varepsilon \approx 0$ is a small positive constant that allows the solution procedure to give first priority on the optimization of $\theta_{i}^{c}$ (in a lexicographic sense), which represents a weighted output/input efficiency ratio for hospital $i$. Denoting by $F^{*}$ the value of the objective function of problem (1) at its optimal solution, hospital $i$ is classified as efficient if and only if $F^{*}=1$ (i.e., if the efficiency score is $\theta_{i}^{C}=1$ and the slacks are zero). Variable returns to scale (VRS) can be introduced by simply adding the convexity constraint $\lambda_{1}+\cdots+\lambda_{N}=1$ to the above model. This constraint ensures that a hospital is benchmarked only against other units of similar size. The resulting model is known as the BCC model (Banker et al., 1984). 
When panel data are available, a commonly used approach to analyze the efficiency changes over time is the Malmquist productivity index (MPI). Denoting by $\left(\mathbf{x}_{i}^{t}, \mathbf{y}_{i}^{t}\right)$ and $\left(\mathbf{x}_{i}^{t+1}, \mathbf{y}_{i}^{t+1}\right)$ the input/output data for a hospital $i$ over periods $t$ and $t+1$, the MPI is expressed as follows (Färe et al., 1992):

$$
\operatorname{MPI}_{i}(t, t+1)=\frac{\theta_{i}^{t+1}\left(\mathbf{x}_{i}^{t+1}, \mathbf{y}_{i}^{t+1}\right)}{\theta_{i}^{t}\left(\mathbf{x}_{i}^{t}, \mathbf{y}_{i}^{t}\right)} \times \sqrt{\frac{\theta_{i}^{t}\left(\mathbf{x}_{i}^{t+1}, \mathbf{y}_{i}^{t+1}\right)}{\theta_{i}^{t+1}\left(\mathbf{x}_{i}^{t+1}, \mathbf{y}_{i}^{t+1}\right)} \times \frac{\theta_{i}^{t}\left(\mathbf{x}_{i}^{t}, \mathbf{y}_{i}^{t}\right)}{\theta_{i}^{t+1}\left(\mathbf{x}_{i}^{t}, \mathbf{y}_{i}^{t}\right)}}
$$

where $\theta_{i}^{t^{\prime}}\left(\mathbf{x}_{i}^{t}, \mathbf{y}_{i}^{t}\right)$ is the (CRS) efficiency score obtained by benchmarking the hospital's data for period $t$ against the sample data for period $t^{\prime}$. MPI values higher than one indicate productivity improvements, whereas low values correspond to productivity decay. The first term in (2) indicates the efficiency change, whereas the square root term represents the technological change (the shift in the efficiency frontier between periods $t$ and $t+1$ ). As shown in Färe et al. (1994), the efficiency change factor can be further decomposed into the pure technical and scale efficiency changes.

In this study an input-oriented DEA setting has been used to assess the technical and scale efficiency of Greek hospitals under two different scenarios, which cover the operational and economic efficiency of the hospitals.

\subsection{Modeling specifications}

The selection of input and output variables that describe the multifaceted operation of health care units is clearly an important factor for evaluating their efficiency status. The review of O’Neill et al. (2008) provides a comprehensive categorization of multiple input and output variables used in DEA-based efficiency analysis studies in the health care sector. As far as the inputs are concerned they identify six major categories, involving beds, clinical staff, nonclinical staff, working hours, services offered, and costs. On the output side, the review indicates that most studies focus on two main categories of variables, namely: (a) medical visits, cases, patients, and surgeries, and (b) inpatient days.

The variables used in this study follow a similar categorization. In particular, we use output variables that take into account the service mix, case mix, outpatient and inpatient cases of Greek public hospitals, based on the nature of services that they provide, as follows:

- External patient care (outpatient and emergency visits).

- Inpatient care (total number of patients in surgical and pathological departments). 
- Surgical operations (minor or major operations).

- Laboratory services (quantity of laboratory and diagnostic tests).

The hospitals' inputs, on the other hand, are categorized into two main categories, related to labor (clinical and non-clinical) and operating costs (staff salaries and medical supplies), as shown in Table 1. In that regard, two modeling schemes are considered, the first focusing on the overall operational/production efficiency of the hospital and the second on their economic efficiency.

Insert Table 1 here

In addition to the above input/output variables, other operating characteristics of the hospitals and the environment in which they operate are also taken into consideration through the second-stage regression analysis.

First, the logarithm of the number of beds and its square are used to take into consideration the size and clinical capacity of the hospitals (the use of the squared variable enables the modeling of non-linear size effects). Several studies have shown that the size of hospitals is closely related to their efficiency. However, the findings are mixed with regard to whether small or large hospitals perform better (Aletras et al., 1997; Asmild et al., 2013; Coyne et al., 2009; Mitropoulos et al., 2013). Leleu et al. (2012) attribute this lack of agreement in the results of different studies to several reasons, such as technical issues (e.g., the different methodologies used), as well as differences in the nature of the data, technology conditions, and the types of units considered in each study.

Except for the capacity and size of the hospitals, the extent to which these are actually used is obviously an important factor. In that regard, the occupancy rate (inpatient days of care/365×beds) is used to take capacity utilization into account. From an economic point of view, Ferrier and Valdmanis (1996) note that hospitals with low occupancy rates have higher costs per case (due to fixed costs). On the other hand, Kooreman (1994) argues that higher occupancy rates improve operational efficiency, since the management will not be able to quickly adapt the staff to fluctuations in the number of patients. Nyman et al. (1989) and Sexton et al. (1989) also link occupancy rates to the staffing policies that hospitals follow, but their results are contradictory, which indicates that the role of occupancy rate may vary depending on whether hospitals are overstaffed or understaffed. In that regard, in order to control for the staffing policies of the hospitals, we employ the beds to doctors ratio (for the 
adequacy of the medical personnel) and the administrative staff to total staff ratio (adequacy of the non-medical personnel).

Furthermore, in order to control for the complexity of the cases handled by the hospitals, we use the average length of stay index. The length of stay is usually employed as an indicator of hospital efficiency, with hospitals having long average lengths of stay considered relatively inefficient. Several studies, however, note that other factors may also affect the length of stay, including case mix complexity and quality issues. For instance, Kooreman (1994) notes that patients with longer stays may represent more severe cases that require more resources. Thomas et al. (1997), further found that the length of stay might also be considered indicative of poor quality care (e.g., when the adoption of cost minimization policies lead to premature discharges or when poor quality of care causes medical complications). On the cost side, Farsi and Filippini (2006) noted that the length of stay also represents a hospital's hotel services (e.g., nursing care and accommodation) and found that it is a significant predictor of cost inefficiency using a sample of Swiss hospitals.

We also take into consideration indicators to measure the specialization of the hospitals. Capkun et al. (2012) argue that specialization may have positive effects on the operational performance of hospitals due to economies of scale and scope, learning effects, patient selection, as well as personnel behavior. However, Lindlbauer and Schreyögg (2014) note that the existing empirical results are inconclusive as to whether specialization has indeed a positive or negative effect and attribute this finding to the different specialization indicators used in past empirical studies. In that regard and taking also into account that our analysis covers both the operational and the economic aspects of the hospitals, we use three indicators, two focused on the case mix and the other focused on the cost structure of the hospitals. On the cost side, we use the ratio between medical supplies cost and the total cost of supplies to take into consideration the effect that the specialization of hospitals and their management practices have on their cost structure. ${ }^{1}$ Regarding the case mix, we first consider the outpatients to inpatients ratio as a way to assess the relative importance of services that a hospital provides to outpatient visits compared to inpatients. In addition, the information theory specialization index proposed by Farley (1989) is also employed:

$$
S_{i}=\sum_{j} w_{i j} \ln \left(w_{i j} / p_{j}\right)
$$

\footnotetext{
${ }^{1}$ The ratio of medical supplies cost to the total cost of supplies is only employed for the analysis of economic efficiency.
} 
where $w_{i j}=N_{i j} / N_{i}$ is the percentage of inpatients $N_{i j}$ for department $j$ of hospital $i$ over the number of inpatients of the hospital $\left(N_{i}\right)$, and $p_{j}=\left(N_{1 j}+N_{2 j}+\ldots\right) /\left(N_{1}+N_{2}+\ldots\right)$ is the overall percentage of inpatients in department $j$ over all hospitals. Given that during the period of the analysis Greek hospitals have not adopted a diagnosis-related group system, the calculation of the above index, is based on a distinction between patients in general medicine, surgery, psychiatric, and emergency departments, as well as intensive, and coronary care units. The above specialization index is close to zero for hospitals with case mix similar to the overall average case mix proportions and increases as a hospital's case mix diverges from the average.

Finally, market structure indicators are also employed. Even though all hospitals in this study are public and consequently they do not operate in a competitive environment, the characteristics of the region in which they operate could have an impact on their efficiency status. Market structure and concentration indicators have been found significant in other studies in the context of for-profit healthcare units (see for example, Ferrier and Valdmanis, 1996; Rosenman et al., 1997). In this study, we first use a simple concentration ratio measured as the ratio between the inpatients in a hospital and the total inpatients in all public hospitals in the same administrative division (patients in private hospitals are not considered in the calculation). We also consider the logarithm of population density for the prefectures in which the hospitals operate, as a proxy of the demand for health care services in each area, as well as the unemployment rate to account for the effect due to the socio-economic conditions in each area.

\section{EMPIRICAL ANALYSIS}

\subsection{Sample data}

The sample of the study consists of 87 public general hospitals operating in the Greek health system during the period 2005 to 2009 . Our initial data included 128 hospitals, but the final choice was made after the adoption of certain criteria related to the health services provided by the hospitals and the characteristics of their case and service mix. In particular, the final set of hospital was specified on the basis of a mix of criteria related to the character (special purpose) of the hospitals (profit-non-profit, public or private), the mix of treatment they provide (general or special hospitals, university or non-university), the mix of cases 
encountered (pathological or surgical cases), and the size of the hospitals (as measured by the number of beds). Thus, the final sample consists of hospitals satisfying the following four criteria:

- Type of hospitals: Non-profit hospitals that are public entities.

- Type of hospitalization: The sample involves only general hospitals, that provide a full range of secondary health care medical services, excluding special hospitals (psychiatric, pediatric, oncology etc.), as well as university hospitals.

- Case mix of services: The hospitals in the sample have services such as: fully operational pathological and surgery departments, laboratory departments, outpatient's services, emergency department and operating rooms to perform surgeries.

- The size of the hospitals: The sample consists of hospitals with more than 60 beds. Thus, we have excluded very small hospitals which operate with low-level technical facilities and do not employ all specialties of staff.

The 87 hospitals in the final sample are geographically distributed over the country, they account for more than $80 \%$ of the total number of Greek public hospitals, and about $83 \%$ of the total bed capacity. Table 2 summarizes the sample descriptive statistics (annual averages and coefficients of variation-CV) for all variables. It is worth noting the significant increase in operating costs (supplies and labor costs) during the time period of the analysis. However, this increase in expenses is not in accordance with the minor changes observed for the volume of medical services provided by the hospitals (i.e., number of inpatients and outpatient visits, number of surgeries and laboratory examinations). Furthermore, there is an evident increase in the average number of medical staff and a decrease in occupancy rate.

Insert Table 2 here

\subsection{Efficiency results}

Table 3 summarizes all annual efficiency results obtained with a contemporaneous scheme, under which a different efficiency frontier is estimated for each year. The results obtained from the operational/production point of view indicate that the efficiency of the hospitals ranged between 80-83\% during the examined period under the CRS approach, and between $86-89 \%$ assuming variable returns to scale. The number of hospitals that have been consistently efficient throughout all years of the analysis is 8 and 19 under the CRS and VRS 
models, respectively. From the perspective of economic efficiency, the CRS results range between $73 \%$ and $77.4 \%$ over the examined time period, whereas the corresponding pure (VRS) economic efficiency ranged between $85 \%$ and $86.5 \%$. Seven hospitals were found to be consistently efficient (throughout all years) with the CRS model, whereas assuming VRS this number increased to 18. All differences between the operational and economic efficiency estimates (CRS, VRS, and scale efficiency scores) are significant at the $1 \%$ level according to the non-parametric Wilcoxon signed ranked test. Interestingly, the coefficient of variation for the efficiency scores derived from the economic model are consistently higher than the ones of the operational efficiency model. This indicates, that the similarities (in efficiency terms) between the hospitals are higher when considering their operating characteristics and the efficiency of their services, whereas larger discrepancies are evident from an economic perspective.

Insert Table 3 here

The scale efficiency estimates for the operational model are consistently higher than $90 \%$ throughout all years. On the other hand, under the economic model, scale efficiency appears to be lower, thus indicating that the effect due to the size of the hospitals is stronger on their economic efficiency, rather than their operational and production efficiency. As shown in Table 4, in both cases, most hospitals operate under decreasing returns to scale (DRS). Under the operational efficiency model, the percentage of hospitals characterized by DRS ranges between 40-56\%, but over the years this has followed a decreasing trend. In fact 2009 has been the first year where IRS prevailed for most of the hospitals. Thus, in terms of operational efficiency, the most recent data indicate that reductions in scale size may not be a proper way of action to achieve further improvements. For the economic efficiency model, the percentage of hospitals operating under DRS range at higher levels (64-72\%) compared to the operational model. On the other hand, the percentage of hospitals operating under constant returns to scale (i.e., at the optimal size) increased in 2008 and 2009. These were the first years after then 2007 reform, thus implying that the reform had a mild success in addressing some scale issues for the economic efficiency of the hospitals.

Insert Table 4 here 
Figure 1 illustrates the relationship between scale efficiency and the size of the hospitals (as measured by the number of beds) over all years of the analysis. The hospitals are grouped into five size categories, defined on the basis of the corresponding percentiles for the number of beds. It is evident that the optimal scale size under the operational model is around 160-230 bends (190 beds on average), whereas in terms of economic efficiency this is approximately 100-150 beds (with an average of 125). These results obtained with the most recent available data, indicate that the optimal scale size for Greek hospitals could actually be a bit lower compared to the earlier results reported in past studies. For instance, Aletras et al. (2007) used data for 2000 and 2003 to assess the operational efficiency of Greek hospitals, and found the optimal scale size to be around 200-300 beds.

Insert Figure 1 here

\subsection{Efficiency changes over time}

The results presented in the previous section provide insights into the efficiency status and characteristics of the hospitals, but given the panel nature of the available data, analyzing the efficiency trends over time, is of particular interest. To explore this issue, the MPI was calculated for each pair of consecutive years. The obtained results (geometric means) are summarized in Table 5 for the overall MPI, as well as all of its components, namely:

a) efficiency change: $\Delta$ (Eff),

a1) pure technical efficiency change: $\Delta(\mathrm{PTE})$,

a2) scale efficiency change: $\Delta(\mathrm{SE})$,

b) technology change: $\Delta$ (Tech).

Insert Table 5 here

From the overall results it is evident that the MPI remained almost consistently below one under both the operational and the economic setting, thus indicating that the productivity of Greek hospitals has declined during the period under consideration. The decline is stronger under the economic model. 
Furthermore, there are interesting differences in the decomposition of the two MPIs for the operational and economic models. In particular, under the operational model, the efficiency change factor $\Delta$ (Eff) fluctuated around one, thus indicating a rather stable efficiency status, whereas the best practice frontier has followed a declining trend (with the exception of 2007-2008), as it is evident from the technology factor $\Delta$ (Tech). The improvement in the best practice frontier in 2007-2008 could be a short-term result of the 2007 administrative reform. Nevertheless, even this temporary improvement in the best practice frontier, has been offset by a decrease in the efficiency factor in 2007-2008 ( $\Delta(E f f)=0.966)$, which is mainly due to the decline in pure technical efficiency $(\Delta(\mathrm{PTE})=0.979)$. This could be attributed to the increased administrative burden that hospitals had to face as a result of the implementation of the reform.

On the other hand, under the economic model, the change in the efficiency of the hospitals has been consistently positive up to 2008 (i.e., $\Delta$ (Eff) $>1$ ), but declined in 2009. At the same time, the best practice frontier has followed a consistent downward trend throughout the examined period. This result is in accordance with the significant increase in the costs that the Greek healthcare system faced over the past decade. The results indicate that this has been the main factor for the declining productivity (from an economic perspective) of Greek hospitals, and supports the recent actions taken at the central level to implement nationwide policies for cost reductions in the Greek healthcare system, focusing primarily on the control of supplies costs. It is worth noticing that the rate of decline in the technology factor (i.e., the rate of contraction of the best practice frontier) has been ameliorated in 2008-2009, the two years following the administrative reform of 2007. During that period, the hospitals' administrations tried to implement cost management policies under the pressure of performance contracts imposed by the central government. However, the accumulating financial problems of pension funds did not allow hospitals to redeem their costs to suppliers and the prices of materials and services continued to rise. Thus, despite these efforts and the mild improvement in the rate of decline in the technology factor, the overall productivity change (MPI) for the economic efficiency model continued to be below one.

The decomposition of the results by the size of the hospitals (Figure 2) indicates that the overall productivity of small hospitals (less than 110 beds) declined during the examined period under both the operational and the economic model. Medium and large hospitals (110324 beds and more than 325 beds, respectively) managed to maintain their performance level from the operational perspective, but their economic productivity decreased. The decline has been clearly more profound for small hospitals and it is mainly attributed to the contraction of 
the best practice frontier, particularly under the economic model. This implies that the increasing costs over the time period of the analysis have placed a heavier burden on smaller hospitals rather than on larger ones.

\section{Insert Figure 2 here}

\subsection{Explaining the efficiency results}

In order to obtain further insights into the factors that describe the efficiency of Greek hospitals, a second-stage regression analysis was performed, using the efficiency scores analyzed in section 4.1 as the dependent variable, which were regressed against the explanatory variables discussed in section 3.2. In addition, we incorporate annual dummy variables to control for the contemporaneous scheme (cross-sectional assessment) used to estimate the efficiency of the hospitals with DEA.

The second-stage regression analysis is based on the double bootstrap algorithm of Simar and Wilson (2007), which first uses a bootstrap approach to obtain bias-corrected efficiency estimates, followed by a second-stage bootstrap to make inferences on the relationship between the efficiency scores and the selected explanatory variables, based on a truncated regression model. In accordance with the recommendations of Simar and Wilson (2007), 500 bootstrap samples were used in the first-stage bootstrap and 5,000 in the secondstage. The analysis was performed in $\mathrm{R}$ with the FEAR package (Wilson, 2008).

Given the strong effect of scale efficiency on the overall efficiency of the hospitals (particularly under the economic model), the second-stage analysis is implemented under the VRS setting. The bootstrap results for the two truncated regression models are illustrated in Table 6. It should be noticed that the independent variables are the same in both models with the exception of the medical supplies cost to total supplies cost ratio, which is only used as an explanatory variable in the economic efficiency model.

Insert Table 6 here

As far as the management of human resources (HR) is concerned, the number of beds to clinical staff has a positive impact on both operational and economic efficiency, whereas the 
ratio of administrative staff to total staff has a significant (negative) effect only on operational efficiency. These results, highlight that the adoption of properly designed HR management systems could significantly improve the efficiency of Greek public hospitals. Even though both clinical and administrative personnel are important factors that drive the operational efficiency of Greek hospitals, in economic terms it is the clinical staff that matters most. This is indeed confirmed by the observations made earlier (cf. the descriptive statistics of Table 2) about the increase of the clinical staff over the years, whereas the number of beds and the administrative personnel has remained almost constant.

Setting proper target levels for the number of personnel should be in accordance with the hospitals' occupancy rates (Nyman et al., 1989). Indeed, occupancy rate is found to have a significant positive effect on operational performance, as hospitals that take advantage of their full bed capacity produce more output from their available recourses (Ferrier and Valdmanis, 1996). Re-organizing the services provided by hospitals located in the same area could lead to improvements in the utilization of the hospitals capacity, thus increasing occupancy rates and ultimately their operational performance. However, it should be noted that in terms of economic efficiency, occupancy rate does not seem to have a significant effect.

On the other hand, the average length of stay has a negative coefficient in both operational and economic efficiency. Thus, hospitals that fail to treat patients in a timely manner or have to handle for more severe cases, are less efficient. Similar results on the negative connection between the average length of stay and the efficiency of hospitals have been reported in previous studies for both Greek hospitals and other countries (see for instance, Ferrier and Valdmanis, 1996; Farsi and Filippini, 2006; Mitropoulos et al., 2013).

The specialization indicator has a positive effect (significant at the $10 \%$ level) on operational efficiency but it is not significant in the economic model. Thus, the productive performance of hospitals that focus on providing special services, is higher compared to hospitals with a more diversified case mix. It is worth noting that recently the Greek government has initiated a plan to reorganize some hospitals focusing on establishing new units providing specialized services to patients. The obtained results suggest that such policies could have positive effects, at least on the operational performance of the hospitals. However, this may not translate to economic efficiency improvements, unless there is a re-structuring of the services that Greek hospital provide, taking into account not only operational and health care provision but also cost containment goals. The obtained results imply that Greek hospitals are not characterized by economies of scope as their economic efficiency is not significantly affected by the diversity of the services they provide (Preyra and Pink, 2006). 
The two additional indicators that take into account specific aspects of the case and cost mix of the hospitals provide some additional insights in that regard. In particular, the outpatients to inpatients ratio is found to have a significant negative effect only in the economic model. The share of medical supplies to total cost also affects negatively economic efficiency. Even though cases treated in outpatient department do not require nursing costs, the negative impact of this variables in the economic model is indicative of the inadequate pricing of outpatient services in Greek hospitals and their failure to collect the corresponding revenues from treating outpatient cases. To address these issues, a new pricing policy has been recently introduced with regard to outpatient visits for all Greek public hospitals, aiming towards increasing outpatient revenues. On the other hand, the significance of the supplies cost ratio is in accordance with the heavy burden that supplies has placed on the Greek NHS over the past decade (for the sample hospitals the cost of medical supplies increased by more than $40 \%$ over the examined period).

The two variables related to the size of the hospitals indicate that larger hospitals are more efficient under both the operational and economic model. Similar results for Greek hospitals have also been reported by Athanassopoulos, and Gounaris (2001). The size effect appears to be stronger for economic efficiency as both variables related to the number of beds have a significant positive contribution. On the other hand, for the operational efficiency model only the squared variable is found significant. These results indicate that larger hospitals achieve economies of scale, thus being able to utilize their clinical resources and costs more efficiently.

Finally, as far as it concerns the three variables characterizing the conditions in the regions in which the hospitals are located (concentration, population density, unemployment), they all affect operational efficiency in a negative way. However, these effects are weak (none of the variables is statistically significant). On the other hand, in terms of economic efficiency, concentration and population density have a significant negative effect. Therefore, hospitals that operate in heavily populated areas with high concentration, are less efficient from an economic perspective. Such hospitals are mostly located in heavily populated islands (e.g., Rhodes, Corfu, Crete) and prefecture capital cities with no other hospitals in close distance. These results extend the ones reported by Athanassopoulos and Gounaris (2001), who found rural hospitals to be less efficient than urban ones. Our results indicate that economic efficiency improvements can be achieved by implementing policies for cost monitoring and management at the regional level and strengthening the collaboration among hospitals operating in the same region. This finding is in accordance with the scope of the 
2007 reform, which focused on re-structuring the Greek NHS through the strengthening of the local administrations.

Finally as far as the annual dummies are concerned, the one corresponding to 2008 has a negative coefficient (significant at the 5\% level) in the operational efficiency model. It is worth noting that 2008 was the first year following the 2007 reform. In that regard, this result may be attributed to the additional administrative burden that hospitals had to face with to the implementation of the reform. The coefficients for years 2007-2009 in the economic model are all positive, but not significant. This is in accordance with the MPI results discussed earlier, indicating that the 2007 reform had only mild success in economic terms.

\section{CONCLUSIONS}

The present study is the first attempt to assess the overall efficiency and its trend over time of NHS health units in Greece after the implementation of major reforms of the last decade and especially from 2001 to 2007 . The analysis was based on a comprehensive set of variables related to the volume and type of services provided by the hospitals, their size, personnel, and costs structure. Furthermore, the efficiency trends over time were explored, together with the factors that explain the efficiency results.

The empirical results showed that over the period prior to the outbreak of the Greek crises, the efficiency of Greek public hospitals deteriorated, mainly in economic terms. The raising supplies cost and the lack of HR management policies (mainly in terms of the medical personnel) have been important driving factors, together with the lack of proper pricing policies for the services they provide. Furthermore, the empirical results indicate that Greek hospitals are characterized by economies of scale but not economies of scope. The last attempt to reform the Greek NHS in 2007 failed to achieve consistent improvements in terms the hospitals' operational efficiency, whereas in economic terms only some weak evidence of success was found. These, however, should be reconsidered through the examination of more recent data that cover the period of the crisis in the country.

On the basis of these results, further policy actions should be taken on establishing welldefined cost containment goals (mainly as far as supplies are concerned), revising the existing reimbursement scheme and strengthening the hospitals revenue collection mechanisms, implementing HR management systems in accordance the hospitals capacity utilization levels and the demand for healthcare services in each region, merging hospitals where needed, promoting the administrative cooperation between hospitals operating in the same region, and 
strengthening the monitoring mechanisms particularly for smaller hospitals and hospitals operating in isolated areas. While past reform attempts (including the one of 2007) mostly focused on restructuring the administrative model and decentralizing the Greek NHS, future policy measures need to focus on well-defined actions with clear targets on the above issues at the hospital and regional level. Some changes towards that direction are already under way, including among others the introduction of diagnosis-related groups and the development of a country-wise management information system that allows the monitoring of the operational and economic activities of the hospitals. The benchmarking and explanatory approach used in this study, together with the obtained findings, could be a particularly useful basis for assessing the success of the new actions taken.

Future research could extent the results of this study towards a number of directions. Among others these include the optimization of the allocation of resources available to the healthcare system (materials, personnel, capital), the consideration of the quality of the provided services as perceived by the patients, as well as the analysis and evaluation of specific measures designed at the hospital level. Extending the analysis to cross-country comparisons with other European countries could also be interesting as many countries share similar difficulties with their NHSs and that would facilitate the design and implementation of best practice guidelines and policies at the European level.

\section{REFERENCES}

Amado, C.A.F. and Dyson, R.G. (2008), “On comparing the performance of primary care providers", European Journal of Operational Research, 185(3), 915-932.

Aletras, V., Jones, A., and Sheldon, T.A. (1997), "Economies of scale and scope", in: Ferguson, B., Sheldon, T.A., and Posnett, J. (eds.), Concentration and Choice in Healthcare, Financial Times Healthcare, London, 23-36.

Aletras, V., Kontodimopoulos, N, Zagouldoudis, A., and Niakas D. (2007), "The short-term effect on technical and scale efficiency of establishing regional health systems and general management in Greek NHS hospitals”, Health Policy, 83, 236-245.

Asmild, M., Hollingsworth, B., and Birch, S. (2013), "The scale of hospital production in different settings: one size does not fit all”, Journal of Productivity Analysis, 40, 197206. 
Athanasopoulos, A., Gounaris, C., and Sissouras A. (1999), "A descriptive assessment of the production and cost efficiency of general hospitals of Greece", Healthcare Management Science, 2, 97-106.

Athanassopoulos, A. and Gounaris, C. (2001), "Assessing the technical and allocative efficiency of hospital operations in Greece and its resource allocation implications", European Journal of Operational Research, 133(2), 416-431.

Banker, R.D., Charnes, A., and Cooper, W.W. (1984), "Some models for estimating technical and scale inefficiencies in data envelopment analysis", Management Science, 30(9), 1078-1092.

Burgess, J.F. and Wilson, P.W. (1998), "Variation in inefficiency among US hospitals", INFOR, 36(3), 84-102.

Capkun, V., Messner, M., and Rissbacher, C. (2012), "Service specialization and operational performance in hospitals", International Journal of Operations \& Production Management, 32(4), 468-495.

Chang, H., Chang, W., Das, S., and Li, S. (2004), "Healthcare regulation and the operating efficiency of hospitals: Evidence from Taiwan", Journal of Accounting and Public Policy, 23, 483-510.

Charnes, A., Cooper, W.W., Lewin, A.Y., and Seiford, L.M. (1994), Data Envelopment Analysis: Theory, Methodology and Applications, Kluwer Academic Publishers, Boston.

Charnes, A., Cooper, W.W., and Rhodes, E. (1978), "Measuring the efficiency of decisionmaking units”, European Journal of Operational Research, 3(4), 429-444.

Chilingerian, J.A. and Sherman, D.H. (1990), "Managing physician efficiency and effectiveness in providing hospital services”, Health Services Management Research, $3(1), 3-15$.

Chilingerian, J.A. and Sherman, D.H (2011), "Health-care applications: From hospitals to physicians, from productive efficiency to quality frontiers", in: Handbook on Data Envelopment Analysis, Cooper, W.W., Seiford, L.M., and Zhu, J. (eds), Springer, New York, 445-493.

Coyne, J.S., Richards, M.T., Short, R., Shultz, K., and Singh, S.G. (2009), "Hospital cost and efficiency: do hospital size and ownership type really matter", Journal of Healthcare Management, 54(3), 163-174.

Dimas, G, Goula, A., and Soulis, S. (2012), "Productive performance and its components in Greek public hospitals", Operational Research, 12(1), 15-27. 
Economou, C. (2010), “Greece: Health system review”, Health Systems in Transition, 12(7), $1-180$.

Färe, R., Grosskopf, S., Lindgren, B., and Roos, P. (1992), "Productivity changes in Swedish pharamacies 1980-1989: A non-parametric Malmquist approach”, Journal of Productivity Analysis, 3(1-2), 85-101.

Färe, R., Grosskopf, S., Norris, M., and Zhang, Z. (1994), "Productivity growth, technical progress, and efficiency change in industrialized countries", American Economic Review, 84(1), 66-83.

Farley, D.E. (1989), "Measuring casemix specialization and the concentration of diagnoses in hospitals using information theory”, Journal of Health Economics, 8(2), 185-207.

Farsi, M. and Filippini. M. (2006), “An analysis of efficiency and productivity in Swiss hospitals", Swiss Journal of Economics and Statistics, 142(1), 1-37.

Ferrier, G. and Valdmanis, V. (1996), "Rural hospital performance and its correlates", Journal of Productivity Analysis, 7, 63-80.

Fizel, T. and Nunnikhoven, S. (1992), "Technical efficiency of for-profit and non-profit nursing homes", Managerial and Decision Economics, 13(5), 429-439.

Garcia-Lacalle, J. and Martin, E. (2010), "Rural vs urban hospital performance in a 'competitive' public health service”, Social Science \& Medicine, 71, 1131-1140.

Giokas, D. (2001), “Greek hospitals: How well the resources are used”, Omega, 29, 73-83.

Grigoroudis, E., Orfanoudaki, E., and Zopounidis, C. (2011), "Strategic performance measurement in a healthcare organisation: A multiple criteria approach based on balanced scorecard", Omega, 40(1), 104-119.

Grosskopf, S., Margaritis, D., and Valdmanis, V. (2001), "Comparing teaching and nonteaching hospitals: A frontier approach (teaching vs. non-teaching hospitals)", Health Care Management Science, 4, 83-90.

Giuffrida, A. and Gravelle, H. (2001), "Measuring performance in primary care: econometric analysis and DEA", Applied Economics, 33(2), 163-175.

Hagen, T.P. and Kaarbøe, O.M. (2006), “The Norwegian hospital reform of 2002: Central government takes over ownership of public hospitals", Health Policy, 76(3), 320-333.

Hansen, P.M., Peters, D.H., Niayesh, H., Singh, L.P., Dwivedi, V., and Burnham G. (2008), "Measuring and managing progress in the establishment of basic health services: the Afghanistan health sector balanced scorecard", The International Journal of Health Planning and Management, 23(2), 107-117. 
Hellowell, M. (2013), "PFI redux? Assessing a new model for financing hospitals", Health Policy, 113(1-2), 77-85.

Hollingsworth, B. (2008), "The measurement of efficiency and productivity of health care delivery”, Health Economics, 17, 1107-1128.

Hollingsworth, B. and Peacock, S. (2008), Efficiency Measurement in Health and Heath Care, Routledge, New York.

Ifanti, A.A., Argyriou, A.A., Kalofonou, F.H., and Kalofonos, H.P. (2013), "Financial crisis and austerity measures in Greece: Their impact on health promotion policies and public health care", Health Policy (forthcoming).

Jacobs, R., Smith, P. and Street, A. (2006), Measuring Efficiency in Health Care: Analytic Techniques and Health Policy, Cambridge University Press, Cambridge.

Kontodimopoulos, N., Nanos, P., and Niakas, D. (2006) "Balancing efficiency of health services and equity of access in remote areas in Greece”, Health Policy, 76, 49-57.

Kounetas, K. and Papathanassopoulos, F. (2013), "How efficient are Greek hospitals? A case study using a double bootstrap DEA approach", The European Journal of Health Economics, 14, 979-994.

Kooreman, P. (1994), "Nursing home care in The Netherlands: a nonparametric efficiency analysis", Journal of Health Economics, 13(3), 301-316.

Leleu, H., Moises, J., and Valdmanis, V. (2012). "Optimal productive size of hospital's intensive care units", International Journal of Production Economics, 136, 297-305.

Lindlbauer, I. and Schreyögg, J. (2014), “The relationship between hospital specialization and hospital efficiency: do different measures of specialization lead to different results?", Health Care Management Science (forthcoming).

Magnussen, J. (1996), "Efficiency measurement and the operationalisation of hospital production", Health Services Research, 31(1), 21-37.

Mitropoulos, P., Mitropoulos, I., and Sissouras, A. (2013), "Managing for efficiency in health care: The case of Greek public hospitals", The European Journal of Health Economics, 14(6), 929-938.

Nedelea, I.N. and Fannin, J.M. (2013), “Analyzing cost efficiency of critical access hospitals", Journal of Policy Modeling, 35, 183-195.

Nyman, J.A., Bricker, D.L., and Link, D. (1989), "Profit incentives and technical efficiency in the production of nursing home care", The Review of Economics and Statistics, 71(4), 586-594. 
O’Neill, L., Rauner, M., Heidenberger, K., and Kraus, M. (2008), “A cross-national comparison and taxonomy of DEA-based hospital efficiency studies", Socio-Economic Planning Sciences, 42(3), 158-189.

O’Reilly, J., Busse, R., Hakkinen, U., Or, Z., Street, A., and Wiley, M. (2012), "Paying for hospital care: the experience with implementing activity-based funding in five European countries", Health Economics, Policy and Law, 7(1), 73-101.

OECD (2012), Health at a Glance: Europe 2012, OECD Publishing. http://dx.doi.org/ $10.1787 / 9789264183896-$ en

Or, Z. (2014), "Implementation of DRG Payment in France: Issues and recent developments", Health Policy (forthcoming).

Ozcan, Y. (2008), Health Care Benchmarking and Performance Evaluation: An Assessment Using Data Envelopment Analysis, Springer, New York.

Preyra, C. and Pink, G. (2006), "Scale and scope efficiencies through hospital consolidations", Journal of Health Economics, 25(6), 1049-1068

Rosenman, R., Siddharthan, K., and Ahern, M. (1997), "Output efficiency of health maintenance organizations in Florida", Health Economics, 6(3), 295-302.

Sari, N. (2003), "Efficiency outcomes of market concentration and managed care", International Journal of Industrial Organization, 21(10), 1571-1589.

Schmid, A. and Ulrich, V. (2013), "Consolidation and concentration in the German hospital market: The two sides of the coin", Health Policy, 109(3), 301-310.

Sexton, T.R., Leiken, A.M., Sleeper, S., and Coburn, A.F. (1989), "The impact of prospective reimbursement on nursing home efficiency”, Medical Care, 27(2), 154-163.

Shelton Brown III, H. and Pagán, J.A. (2006), "Managed care and the scale efficiency of US hospitals", International Journal of Health Care Finance and Economics, 6(4), 278-289.

Simar, L. and Wilson, P.W. (2007), "Estimation and inference in two-stage, semi-parametric models of production processes", Journal of Econometrics, 136(1), 31-64.

Simoes, P. and Marques, R., (2011), "Performance and congestion analysis of the Portuguese hospital services", Central European Journal of Operational Research, 19, 39-63.

Steinmann, L., Dittrich, G., Karmann, A., and Zweifel, P. (2004), "Measuring and comparing the (in)efficiency of German and Swiss hospitals", European Journal of Health Economics, 5(3), 216-226.

Sulku, S.N. (2012), “The health sector reforms and the efficiency of public hospitals in Turkey: provincial markets", European Journal of Public Health, 22(5), 634-638. 
Thomas, J.W., Guire, K.E., and Horvat, G.G. (1997), "Is patient length of stay related to quality of care?", Hospital and Health Services Administration, 42(4), 489-507.

Tiemann, O., Schreyögg, J., and Busse, R. (2012), "Hospital ownership and efficiency: A review of studies with particular focus on Germany", Health Policy, 104(2), 163-171.

Wilson, P.W. (2008), "FEAR 1.0: A software package for frontier efficiency analysis with R”, Socio-Economic Planning Sciences 42, 247-254.

Worthington, A.C. (2004), "Frontier efficiency measurement in health care: A review of empirical techniques and selected applications", Medical Care Research and Review, 61(2), 135-170.

Vandoros, S. and Stargardt, T. (2013), "Reforms in the Greek pharmaceutical market during the financial crisis", Health Policy, 109(1), 1-6.

Zavras, A., Tsakos, G., Economou, C., and Kyriopoulos, J. (2002), "Using DEA to evaluate efficiency and formulate policy within a Greek national primary health care network", Journal of Medical Systems, 26, 285-292. 
Table 1: Model specifications

\begin{tabular}{ll}
\hline \multicolumn{1}{c}{ INPUTS } & \multicolumn{1}{c}{ OUTPUTS } \\
\hline Operational efficiency & Inpatients \\
Clinical staff & Surgeries \\
Nurses & Outpatient and emergency visits \\
Administrative staff & Laboratory examinations \\
Economic efficiency & \\
Personnel expenses & \\
Supplies expenses & \\
\hline
\end{tabular}


Table 2: Descriptive statistics (averages and coefficients of variation) for all input/output and second-stage variables

\begin{tabular}{|c|c|c|c|c|c|c|c|c|c|c|}
\hline & \multicolumn{2}{|c|}{2005} & \multicolumn{2}{|c|}{2006} & \multicolumn{2}{|c|}{2007} & \multicolumn{2}{|c|}{2008} & \multicolumn{2}{|c|}{2009} \\
\hline & Avg. & $\mathrm{CV}$ & Avg. & $\mathrm{CV}$ & Avg. & $\mathrm{CV}$ & Avg. & $\mathrm{CV}$ & Avg. & $\mathrm{CV}$ \\
\hline Beds & 249 & 0.76 & 248 & 0.74 & 249 & 0.75 & 250 & 0.75 & 250 & 0.77 \\
\hline Clinical staff & 171 & 0.86 & 178 & 0.87 & 181 & 0.85 & 185 & 0.83 & 191 & 0.82 \\
\hline Nurses & 294 & 0.75 & 292 & 0.75 & 296 & 0.74 & 294 & 0.72 & 289 & 0.73 \\
\hline Admin. \& other staff & 230 & 0.75 & 226 & 0.74 & 224 & 0.74 & 221 & 0.73 & 221 & 0.71 \\
\hline Supplies costs ${ }^{*}$ & 12,954 & 1.27 & 14,150 & 1.26 & 16,176 & 1.27 & 17,874 & 1.30 & 18,560 & 1.32 \\
\hline Medical supplies costs* & 7,086 & 1.33 & 7,664 & 1.32 & 8,861 & 1.35 & 9,726 & 1.35 & 10,065 & 1.41 \\
\hline Pharmaceutical costs* & 5,869 & 1.33 & 6,486 & 1.31 & 7,315 & 1.32 & 8,147 & 1.38 & 8,495 & 1.36 \\
\hline Personnel expenses* & 16,138 & 0.67 & 16,473 & 0.67 & 16,959 & 0.66 & 17,368 & 0.65 & 17,844 & 0.64 \\
\hline Medical staff costs* & 4,542 & 0.69 & 4,814 & 0.70 & 5,010 & 0.69 & 5,249 & 0.67 & 5,558 & 0.65 \\
\hline Admin. staff costs ${ }^{*}$ & 11,596 & 0.68 & 11,659 & 0.67 & 11,949 & 0.66 & 12,119 & 0.65 & 12,286 & 0.65 \\
\hline Inpatients & 15,039 & 0.75 & 15,165 & 0.74 & 15,267 & 0.77 & 15,340 & 0.80 & 15,183 & 0.76 \\
\hline Surgeries & 3,748 & 0.87 & 3,751 & 0.89 & 3,906 & 1.03 & 3,836 & 0.91 & 3,822 & 0.87 \\
\hline Laboratory exams ${ }^{* *}$ & 1,263 & 1.06 & 1,322 & 1.15 & 1,355 & 1.05 & 1,376 & 1.02 & 1,451 & 1.02 \\
\hline Emerg. \& outpat. visits ${ }^{* *}$ & 106 & 0.56 & 108 & 0.56 & 107 & 0.55 & 108 & 0.60 & 107 & 0.60 \\
\hline Beds/Clinical staff & 1.59 & 0.31 & 1.54 & 0.30 & 1.50 & 0.26 & 1.46 & 0.26 & 1.41 & 0.26 \\
\hline Admin. staff / Total staff $(\%)$ & 33.49 & 0.14 & 33.02 & 0.14 & 32.40 & 0.14 & 31.94 & 0.15 & 32.11 & 0.12 \\
\hline Avg. length of stay & 4.06 & 0.26 & 4.08 & 0.27 & 3.99 & 0.28 & 4.00 & 0.28 & 4.03 & 0.30 \\
\hline Occupancy rate $(\%)$ & 65.28 & 0.21 & 65.76 & 0.22 & 63.59 & 0.22 & 63.29 & 0.23 & 63.30 & 0.25 \\
\hline Outpat./Inpatients (\%) & 59.97 & 0.26 & 57.17 & 0.24 & 56.59 & 0.26 & 56.63 & 0.27 & 55.81 & 0.27 \\
\hline Specialization (\%) & 7.91 & 1.44 & 8.97 & 1.57 & 7.95 & 1.01 & 7.48 & 0.91 & 7.52 & 0.90 \\
\hline Concentration (\%) & 2.98 & 0.87 & 3.03 & 0.87 & 3.04 & 0.87 & 3.03 & 0.90 & 3.04 & 0.92 \\
\hline Med. sup. cost / Supplies cost (\%) & 53.71 & 0.19 & 53.16 & 0.19 & 53.42 & 0.20 & 53.70 & 0.20 & 53.65 & 0.21 \\
\hline
\end{tabular}

* In thousand euros, ** In thousands 
Table 3: Annual efficiency statistics (averages, coefficients of variation and number of efficient hospitals in parentheses)

\begin{tabular}{|c|c|c|c|c|c|c|c|}
\hline & & & 2005 & 2006 & 2007 & 2008 & 2009 \\
\hline \multirow{9}{*}{ 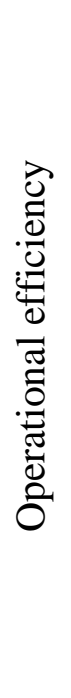 } & CRS & Mean efficiency & 82.69 & 82.29 & 82.82 & 80.08 & 83.31 \\
\hline & & Coef. of variation & 0.17 & 0.16 & 0.17 & 0.18 & 0.18 \\
\hline & & Efficient hospitals & 19 & 13 & 16 & 13 & 21 \\
\hline & VRS & Mean efficiency & 89.04 & 88.98 & 87.80 & 86.01 & 88.44 \\
\hline & & Coef. of variation & 0.14 & 0.14 & 0.16 & 0.16 & 0.15 \\
\hline & & Efficient hospitals & 38 & 33 & 33 & 29 & 37 \\
\hline & Scale & Mean efficiency & 92.84 & 92.50 & 94.35 & 93.17 & 94.24 \\
\hline & & Coef. of variation & 0.09 & 0.09 & 0.08 & 0.09 & 0.10 \\
\hline & & Efficient hospitals & 19 & 13 & 16 & 13 & 21 \\
\hline \multirow{9}{*}{ 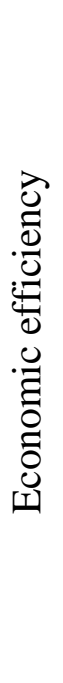 } & CRS & Mean efficiency & 73.07 & 75.57 & 76.70 & 77.35 & 77.25 \\
\hline & & Coef. of variation & 0.22 & 0.21 & 0.21 & 0.21 & 0.21 \\
\hline & & Efficient hospitals & 10 & 12 & 14 & 17 & 16 \\
\hline & VRS & Mean efficiency & 85.99 & 84.95 & 85.94 & 86.53 & 86.30 \\
\hline & & Coef. of variation & 0.18 & 0.19 & 0.18 & 0.18 & 0.18 \\
\hline & & Efficient hospitals & 33 & 33 & 31 & 34 & 38 \\
\hline & Scale & Mean efficiency & 85.46 & 89.56 & 89.71 & 89.84 & 90.02 \\
\hline & & Coef. of variation & 0.15 & 0.14 & 0.13 & 0.13 & 0.14 \\
\hline & & Efficient hospitals & 10 & 12 & 14 & 17 & 16 \\
\hline
\end{tabular}


Table 4: Percentage of hospitals operating in different types of returns to scale (decreasingDRS, increasing-IRS, constant-CRS)

\begin{tabular}{|c|c|c|c|c|c|c|}
\hline & \multicolumn{3}{|c|}{ Operational model } & \multicolumn{3}{|c|}{ Economic model } \\
\hline & DRS & IRS & CRS & DRS & IRS & CRS \\
\hline 2005 & 56.3 & 32.2 & 11.5 & 72.4 & 21.8 & 5.7 \\
\hline 2006 & 54.0 & 39.1 & 6.9 & 65.5 & 27.6 & 6.9 \\
\hline 2007 & 46.0 & 41.4 & 12.6 & 72.4 & 20.7 & 6.9 \\
\hline 2008 & 49.4 & 39.1 & 11.5 & 64.4 & 20.7 & 14.9 \\
\hline 2009 & 39.1 & 43.7 & 17.2 & 69.0 & 20.7 & 10.3 \\
\hline
\end{tabular}

Table 5: Malmquist productivity index and its decomposition

\begin{tabular}{lcccccc}
\hline & & MPI & $\Delta($ Eff $)$ & $\Delta$ (Tech) & $\Delta($ PTE $)$ & $\Delta(\mathrm{SE})$ \\
\hline \multirow{3}{*}{ Operational } & $2006-07$ & 0.992 & 1.005 & 0.987 & 0.984 & 1.021 \\
efficiency & $2007-08$ & 1.003 & 0.966 & 1.038 & 0.979 & 0.987 \\
& $2008-09$ & 0.984 & 1.040 & 0.946 & 1.029 & 1.010 \\
\hline \multirow{3}{*}{ Economic } & $2005-06$ & 0.942 & 1.037 & 0.909 & 0.985 & 1.052 \\
efficiency & $2006-07$ & 0.922 & 1.017 & 0.907 & 1.014 & 1.002 \\
& $2008-08$ & 0.942 & 1.007 & 0.936 & 1.006 & 1.001 \\
& 2009 & 0.971 & 0.999 & 0.973 & 0.998 & 1.001 \\
\hline
\end{tabular}


Table 6: Second-stage truncated regression results for the VRS efficiency estimates (bootstrap estimates and confidence intervals)

\begin{tabular}{lcccc}
\hline & \multicolumn{2}{c}{ Operational model } & \multicolumn{2}{c}{ Economic model } \\
\cline { 2 - 5 } & Coef. & $p$-value & Coef. & $p$-value \\
\hline Beds/Clinical staff & $0.214^{*}$ & 0.000 & $0.087^{*}$ & 0.000 \\
Administrative staff / Total staff & $-0.929^{*}$ & 0.000 & 0.097 & 0.508 \\
Avg. length of stay & $-0.055^{*}$ & 0.000 & $-0.066^{*}$ & 0.000 \\
Occupancy rate & $0.283^{*}$ & 0.000 & -0.038 & 0.474 \\
Outpatients / Inpatients & -0.026 & 0.523 & $-0.187^{*}$ & 0.000 \\
Specialization & 0.094 & 0.081 & -0.004 & 0.935 \\
Ln(Beds) & -0.003 & 0.676 & $0.067^{*}$ & 0.000 \\
[Ln(Beds) ${ }^{2}$ & $0.045^{*}$ & 0.000 & $0.053^{*}$ & 0.000 \\
Medical supplies cost / Total supplies cost & - & & $-0.340^{*}$ & 0.000 \\
Concentration & -0.310 & 0.214 & $-3.159^{*}$ & 0.000 \\
Ln(Population density) & -0.008 & 0.198 & $-0.023^{*}$ & 0.002 \\
Unemployment & -0.372 & 0.309 & -0.077 & 0.840 \\
2006 & 0.004 & 0.780 & -0.003 & 0.868 \\
2007 & -0.014 & 0.418 & 0.014 & 0.476 \\
2008 & $-0.044^{*}$ & 0.014 & 0.019 & 0.347 \\
2009 & 0.016 & 0.326 & 0.023 & 0.222 \\
Constant & $0.892^{*}$ & 0.000 & $1.348^{*}$ & 0.000 \\
\hline$\sigma$ & 0.091 & & 0.108 & \\
Log likelihood & 504.284 & & 425.778 & \\
\hline
\end{tabular}

* Significant at the $5 \%$ level. 


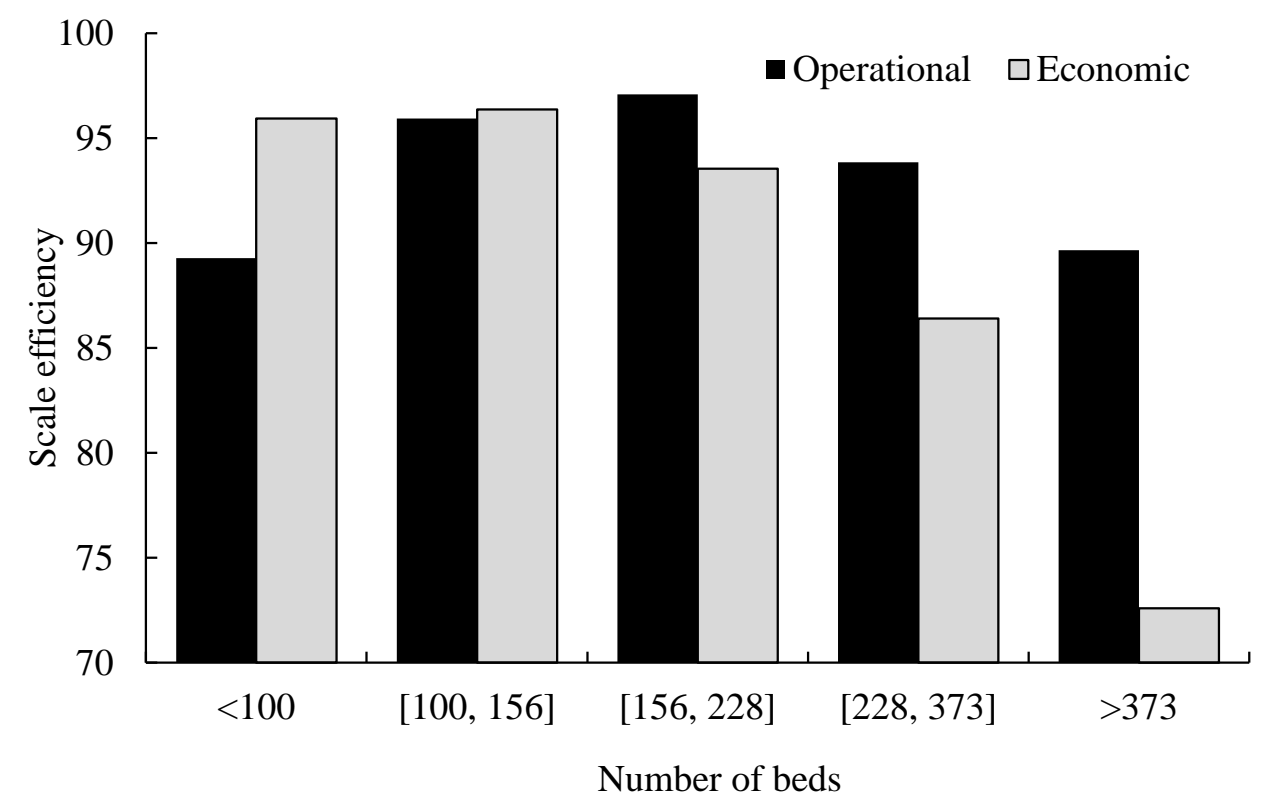

Figure 1: Scale efficiencies by the size of the hospitals (averages over all years)
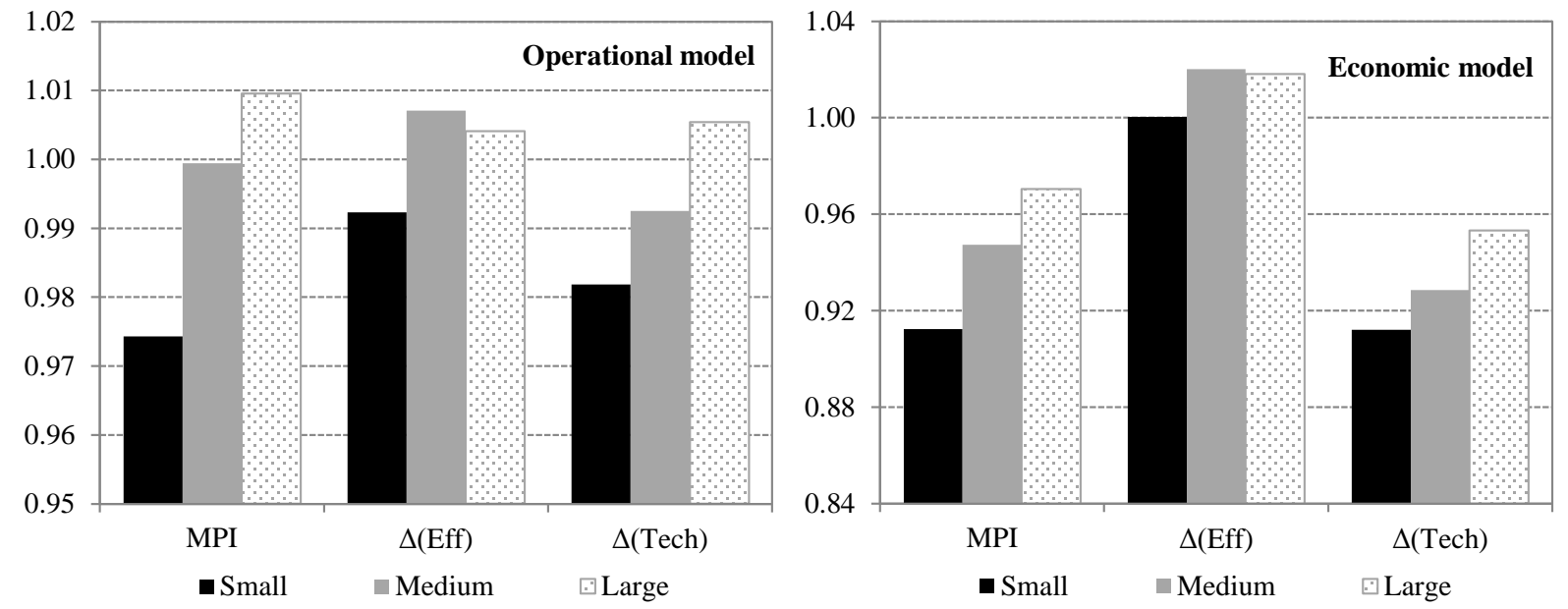

Figure 2: The Malmquist index and its main constituents by the size of the hospitals 